\title{
Implicit Theories of Emotion: Affective and Social Outcomes Across a Major Life Transition
}

\author{
Maya Tamir \\ Boston College
}

Sanjay Srivastava
University of Oregon

\author{
Oliver P. John \\ University of California, Berkeley
}

James J. Gross

Stanford University

\begin{abstract}
The authors demonstrate that people differ systematically in their implicit theories of emotion: Some view emotions as fixed (entity theorists), whereas others view emotions as more malleable (incremental theorists). Using a longitudinal and multimethod design, the authors show that implicit theories of emotion, as distinct from intelligence, are linked to both emotional and social adjustment during the transition to college. Before entering college, individuals who held entity (vs. incremental) theories of emotion had lower emotion regulation self-efficacy and made less use of cognitive reappraisal (Part 1). Throughout their first academic term, entity theorists of emotion had less favorable emotion experiences and received decreasing social support from their new friends, as evidenced by weekly diaries (Part 2). By the end of freshman year, entity theorists of emotion had lower well-being, greater depressive symptoms, and lower social adjustment as indicated in both self- and peer-reports (Part 3). The emotional, but not the social, outcomes were partially mediated by individual differences in emotion regulation self-efficacy (Part 4). Together, these studies demonstrate that implicit theories of emotion can have important long-term implications for socioemotional functioning.
\end{abstract}

Keywords: implicit beliefs, emotion regulation, well-being, social adjustment

The idea that individuals can control their emotions has had currency since the dawn of recorded history. In the Old Testament, one of the earliest messages God sent to Cain was that desire can lead to sin and that people must govern their desire (Gen. 4:7). Implicit in this injunction is the idea that people have the ability to control their emotions. However, there have always been those who have taken the opposite viewpoint, believing that emotions are uncontrollable. For example, Shakespeare's (1603/1992) Hamlet described human behavior as shaped by higher powers, rendering attempts at controlling emotions futile. Similarly, Bedier (1900) described Tristan and Isolde's love as a carriage pulled by wild horses that cannot be tamed, ultimately driving them to their doom. These texts suggest that individuals differ in their beliefs about the controllability of emotions. As in the case of Tristan and Isolde, such texts also suggest that these beliefs can have important long-term implications.

In the present study, we examine individual differences in beliefs about the controllability of emotions and their implications

Maya Tamir, Department of Psychology, Boston College; Oliver P. John, Department of Psychology, University of California, Berkeley; Sanjay Srivastava, Department of Psychology, University of Oregon; James J. Gross, Department of Psychology, Stanford University.

This research was supported by National Institute of Mental Health Grant MH58147.

Correspondence concerning this article should be addressed to Maya Tamir, Department of Psychology, Boston College, McGuinn Hall, 140 Commonwealth Avenue, Chestnut Hill, MA 02467. E-mail: tamirm@bc.edu for emotional and social functioning. We first review research on implicit theories (i.e., beliefs about the malleability of human attributes). We then discuss how such theories might apply to emotion, suggesting that people differ in the extent to which they believe emotions can be controlled. We present a longitudinal study to test whether the belief that emotions are malleable is beneficial for emotional and social functioning, particularly during a period of transition.

\section{IMPLICIT THEORIES}

Beliefs imply certain expectancies, which in turn, guide behavior (Olson, Roese, \& Zanna, 1996). In particular, beliefs about controllability guide the way people construe their reality and influence their motivation to engage in self-regulation (Bandura, 1986; Seligman, 1975). On the basis of these assumptions, Dweck and her colleagues (for reviews, see Dweck, 1986, 1996, 1999; Dweck, Chiu, \& Hong, 1995a; Dweck \& Leggett, 1988) have studied beliefs about the malleability of personal attributes. Because these beliefs tend to be implied rather than explicitly held, they have been referred to as implicit theories.

Dweck and her colleagues have distinguished between entity theories and incremental theories. Individuals who hold incremental beliefs view attributes as malleable and controllable. Such beliefs lead them to make flexible, contextual interpretations of events. In the face of challenge, these beliefs promote assertive attempts at self-regulation, increasing the chances of successful behavior. On the other hand, individuals who hold entity beliefs view attributes as fixed and impossible to control. Such beliefs 
often lead them to make stable, internal attributions. In the face of challenge, these beliefs decrease the motivation to self-regulate, leading to self-regulation failure (for a review, see Dweck, 1996).

Most research on implicit theories has focused on intelligence. Implicit theories of intelligence have been associated with goals in academic settings, responses to academic failure, and performance outcomes (Dweck, 1986, 1996, 1999). Implicit theories, however, are domain-specific. Theories regarding one personal attribute (e.g., intelligence) might be largely independent of theories regarding another personal attribute (e.g., moral character). Such domain specificity has been demonstrated in research distinguishing implicit theories of intelligence from implicit theories of morality (Chiu, Dweck, Tong, \& Fu, 1997; Dweck et al., 1995a) and personality (Beer, 2002; Chiu, Hong, \& Dweck, 1997; Hong, Chiu, Dweck, \& Sacks, 1997).

Implicit theories in a specific domain lead to outcomes within that domain (Dweck, 1996). For example, incremental beliefs about intelligence have been linked to academic performance (Dweck, 1996; Dweck \& Leggett, 1988), whereas incremental beliefs about morality have been linked to judgments of moral character (Chiu, Dweck, Tong, \& Fu, 1997). In addition to such intrapersonal implications, implicit theories can have interpersonal implications. For example, Chiu and colleagues (Chiu, Hong, \& Dweck, 1997) have suggested that entity theorists judge others in terms of stable dispositions, whereas incremental theorists are more sensitive to situational determinants of behavior. In particular, they found that individuals who held entity theories of morality viewed an immoral act as an indication of immoral character and, therefore, tended to be more critical and more likely to punish others (Chiu, Dweck, et al., 1997; Erdley \& Dweck, 1993). Thus, implicit theories might influence both personal and interpersonal outcomes.

\section{IMPLICIT THEORIES OF EMOTION}

To date, research on implicit theories has focused primarily on trait-like attributes, such as intelligence and personality. However, people also might have implicit theories about more transient attributes, such as emotion (for a related discussion on lay theories of emotion, see Ben-Artzi \& Mikulincer, 1996). The examination of implicit theories of emotion is particularly important, given the pervasive impact of emotion on human psychological and social functioning.

Given that emotion and intelligence involve distinct domains, we expected implicit theories of emotion to be distinct from those of intelligence. We further expected emotions to be seen as somewhat more malleable than intelligence. This expectation flowed from the fact that emotion and intelligence differ in their temporal characteristics: Whereas intelligence is a more trait-like attribute, emotions are transient states (e.g., Chaplin, John, \& Goldberg, 1988).

Because implicit beliefs have domain-specific implications (Dweck et al., 1995a), we expected implicit theories of emotion to be linked to emotion-relevant outcomes. Existing research has emphasized the link between implicit theories and domain-specific outcomes related to self-regulation, intrapersonal, and interpersonal experiences (for reviews, see Dweck, 1999; Dweck et al., 1995a). Building on this research, we sought to test whether implicit theories of emotion are linked to emotion regulation, emotional and social experience during a transition.

We chose to focus on a period of transition because we thought individual differences in implicit theories should be particularly influential during challenging transition periods (Henderson \& Dweck, 1990). This is because during transitions, preexisting knowledge and beliefs guide the way individuals perceive and respond to their environment. The transition to college is a life transition, during which many students confront new personal challenges and learn to cope with multiple demands (Cantor, Norem, Niedenthal, Langston, \& Brower, 1987). This transition also disrupts existing networks of social support, separating individuals from high school friends and family and forcing them to form new relationships (Shaver, Furman, \& Buhrmester, 1985). If implicit beliefs about emotion are linked to emotional and social experiences, such relations should be evident during this important transition period. Therefore, the present investigation examines implicit theories of emotion during the transition to college.

\section{IMPLICIT THEORIES OF EMOTION AND EMOTION REGULATION}

Implicit theories of intelligence are related to the regulation of intellectual functioning. Individuals who view intelligence as fixed are less likely to try to modify their intellectual functioning (Dweck, 1986; Hong, Chiu, Dweck, Lin, \& Wan, 1999). Following the same logic, we propose that implicit theories of emotion might be related to the regulation of emotion.

First, implicit theories of emotion should be related to emotion regulation efficacy. Individuals who believe emotions are fixed should be less likely to believe that they can actually modify their own emotions. On the other hand, individuals who believe emotions are malleable should be more likely to believe that they possess the ability to control their emotions.

Second, individuals with entity theories of emotion should be less likely to use antecedent (i.e., anticipatory) strategies of emotion regulation. Cognitive reappraisal, for example, is an antecedent-focused strategy that involves construing an emotioneliciting event in a way that changes its emotional impact before it occurs (Gross, 1998; Gross \& John, 2003). Individuals who view emotion as fixed have little incentive to try to modify their emotions by using antecedent strategies such as cognitive reappraisal. On the other hand, individuals who view emotion as malleable should try to actively modify their emotions by changing their appraisal of emotion-eliciting events.

Third, associations between implicit theories of emotion and emotion regulation strategies need not have a one-size-fits-all quality. In its everyday usage, the term emotion often calls to mind emotion experience rather than emotion expression. In fact, individuals frequently separate the experience of emotion from its expression (e.g., Gross, John, \& Richards, 2000). This, in part, is because individuals are able to suppress or mask the expression of their feelings in certain situations without modifying their emotion experience (Gross, 1998; Gross et al., 2000). This suggests that implicit theories of emotion might be focused on emotion experience and thus have little or no bearing on emotion expression. If so, we would not expect implicit theories of emotion to have similar associations with reappraisal and expressive suppression. 
In summary, we expected implicit theories of emotion to be related to emotion regulation efficacy and the use of reappraisal. However, we did not expect such associations with the use of suppression. This is because we did not expect participants' beliefs about the malleability of emotion experience to influence their attempts to modify the overt expressions of their emotion in accordance with social or personal norms (e.g., Hochschild, 1979).

We tested these predictions in Part 1 of our investigation. In Part 1 , we also measured individual differences in emotional intensity. Because strong emotions are harder to control, individuals with stronger emotional experiences might be less successful at emotion regulation and view emotions as less amenable to control. Therefore, in Part 1, we also tested whether the relations between implicit theories of emotion and emotion regulation are evident even when individual differences in emotional intensity are controlled.

\section{IMPLICIT THEORIES OF EMOTION AND EMOTIONAL OUTCOMES}

Implicit theories of intelligence influence academic performance: Individuals who hold entity theories of intelligence tend to perform worse academically (e.g., Dweck, 1999). Similarly, we expected implicit theories of emotion to be related to emotional experience, with entity (vs. incremental) theories associated with less favorable emotion outcomes. If implicit theories of emotion influence emotion experience, individuals who hold entity theories should experience fewer positive and more negative emotions. Such patterns of emotion experience might be established prior to the transition into college and might be maintained as students go through the transition. We tested these hypotheses in Part 2 of the investigation, in which students provided weekly reports about their emotional experiences throughout the first academic term.

\section{IMPLICIT THEORIES OF EMOTION AND SOCIAL OUTCOMES}

During the first term in college, individuals typically need to develop an entirely new social network. Being away from family and childhood friends, students begin to develop new interpersonal relationships (Shaver et al., 1985). During this period, beliefs about emotion might influence the way individuals approach, relate, and respond to others. Specifically, entity theories of emotion might lead individuals to be less tolerant of the emotions of others (see Chiu, Hong, \& Dweck, 1997), gradually leading to fewer and fewer supportive social relationships.

To the extent that implicit theories of emotion influence social outcomes, the effects might not necessarily be evident immediately. Rather, as with relationships themselves, these patterns can only develop over time, as people have a chance to know one another and emerging friendships are put to the test. Therefore, one might expect implicit theories of emotion to have some influence on the development of novel relationships (i.e., involving college friends) but not on well-established relationships (e.g., involving parents). Individuals who hold entity (vs. incremental) theories of emotion might have less control over their own emotions, or they might cultivate more rigid attitudes toward the emotions of others. We tested this possibility in Part 2 of the investigation, in which students reported on the support they received from college friends as well as from parents over the course of their first academic term in college.

\section{IMPLICIT THEORIES OF EMOTION AND LONG- TERM OUTCOMES}

One important question is whether implicit theories of emotion are associated with longer term outcomes. One possibility is that they are not. During the transition into college, implicit theories of emotion might determine the way individuals react initially to personal and social challenges. However, as individuals learn to navigate their new environment, the effects of implicit theories of emotion might wane or vanish altogether. A second possibility, however, is that by helping shape an individual's personal and social environment, implicit theories of emotion might set in motion an adjustment pattern that is maintained over time.

To assess whether the effects of implicit theories are temporary or whether they persist, researchers must examine the effects of implicit theories over relatively long periods of time (Dresel, 2001; Fowler \& Peterson, 1981). Because evidence for the long-term implications of implicit theories is limited (for exceptions, see Henderson \& Dweck, 1990; Robins \& Pals, 2002), we believe it is essential to test whether implicit theories of emotion carry important implications for the transition to college and whether these implications persist over time.

In light of our earlier hypotheses, we expected incremental theories of emotion to predict more favorable emotion experiences and better psychological adjustment over time, as indicated by greater well-being and fewer depressive symptoms. Furthermore, we expected incremental theories of emotion to predict better social outcomes even 1 year following the assessment of such theories. Indeed, social adjustment and "fitting in" are important indicators of successful adaptation to the college environment. In fact, Astin (1993) has shown that social experiences are the strongest determinants of students' satisfaction with the overall college experience. To test these predictions, we included self- and peer reports of emotional and social functioning at the end of freshman year in Part 3 of this investigation.

\section{THE MEDIATING ROLE OF EMOTION REGULATION SELF-EFFICACY}

To the extent that implicit theories of emotion are associated with important personal and social outcomes, it would be valuable to begin to learn what processes mediate these effects. According to the health belief model (Rosenstock, 1974; Rosenstock, Strecher, \& Becker, 1988), the general belief that health is malleable leads to beliefs about one's personal ability to change one's own health which, in turn, promote successful self-regulation. Indeed, there is some evidence that perceived self-efficacy mediates the impact of implicit beliefs on task performance (Tabernero \& Wood, 1999).

Using a similar logic, but now in the domain of emotion, we expected that the effects of implicit theories of emotion would be mediated by beliefs about emotion regulation self-efficacy. Although emotion regulation can involve changing emotions in a variety of ways (Gross, 1998), the vast majority of emotion regulation episodes involve attempts to decrease negative emotions and to increase positive emotions (Gross, Richards, \& John, 2006). 
Indeed, emotion regulation self-efficacy has been associated with favorable emotion experiences and lower depression (e.g., Catanzaro \& Mearns, 1990). Therefore, considering emotional outcomes, emotion regulation self-efficacy could be a promising mediator.

What about social outcomes? On the one hand, emotion regulation has some important social consequences (e.g., Gross \& John, 2003; Lopes, Salovey, Cote, \& Beers, 2005). Therefore, one possibility is that implicit theories of emotion lead to social outcomes via their influence on emotion regulation self-efficacy. On the other hand, social outcomes might depend less on beliefs the individual has about him- or herself and more on interpersonal beliefs and expectations about others that also arise from implicit emotion theories. One alternative hypothesis, therefore, is that implicit theories of emotion lead to social outcomes by mechanisms that are distinct from emotion regulation self-efficacy (see Chiu, Hong, \& Dweck, 1997). In Part 4 of this investigation, we began to address these possibilities.

\section{THE PRESENT STUDY}

To examine the links between implicit theories of emotion and emotional and social outcomes during a time of transition, we drew data from a longitudinal study of the transition to college life in a sample of students at Stanford University. For conceptual clarity, we have organized these data into four parts following a linear timeline. As shown in Figure 1, we measured implicit theories among students just before they entered college (Part 1). We then monitored emotional and social experiences repeatedly as students adjusted throughout their first academic term (Part 2). To test whether implicit emotion theories had any persistent long-term effects, we examined emotional and social adjustment at the end of freshman year (Part 3). After testing the implications of implicit theories of emotion in Parts 1-3, we began to explore one potential mediating mechanism in Part 4, namely self-efficacy in emotion regulation.

\section{Method}

\section{Part 1: Relations to Emotion Regulation Before the Transition to College}

\section{Participants}

Data were available for 437 students (56\% female, $44 \%$ male; age: $M=18.22, S D=0.66$ ). The sample was composed of $59 \%$ Caucasians, 29\% Asians, 12\% Latinos, 5\% African Americans, and $4 \%$ Native Americans, including those who identified themselves as multiracial. Various subsets of this sample participated in subsequent parts of the investigation, as described in the following paragraphs.

\section{Implicit Theories}

Implicit theories of intelligence. Beliefs about the fixed (vs. malleable) nature of intelligence were assessed with the Implicit Theories of Intelligence Scale (Dweck, 1999), which consists of four statements about the fixed nature of intelligence (e.g., "To be honest, people can't really change how intelligent they are," "People can learn new things, but they can't really change their basic intelligence"). Respondents rated the degree to which they agreed with each statement on a 5 -point scale $(1=$ strongly disagree, $5=$ strongly agree). Following Dweck (1999), ratings of all four items were reversed and averaged to form an incremental theory scale ( $\alpha=.95$ ), so that, consistent with previous scoring procedures, higher scores indicate incremental theories and lower scores indicate entity theories of intelligence.

Implicit theories of emotion. To measure beliefs about the malleable nature of emotion, we modified items from the Implicit

Part 4:

Mediation by

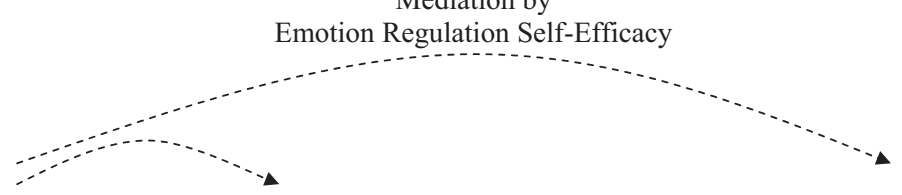

Part 1:

Implicit Theories

and Relations to

Emotion Regulation
Part 2:

Weekly Dairies --

Emotional and Socia

Outcomes
Part 3:

Long-Term Self and Peer-Rated Outcomes

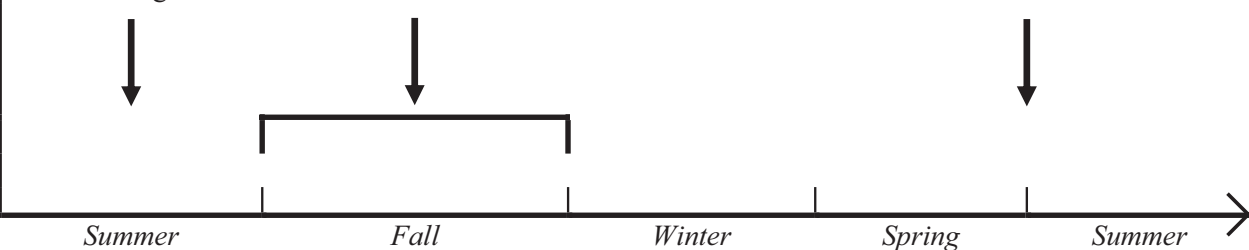

Freshman year

Figure 1. Implicit theories of emotion and the transition to college: Timeline of Parts 1-4 of the investigation. 
Theories of Intelligence Scale (Dweck, 1999) to refer to beliefs about the fixed versus malleable nature of emotion. The scale includes two incremental items, "Everyone can learn to control their emotions," "If they want to, people can change the emotions that they have," and two entity items, "No matter how hard they try, people can't really change the emotions that they have," "The truth is, people have very little control over their emotions." To compute an overall score, we reverse scored the two entity items and then averaged across all items $(\alpha=.75)$ so that, consistent with beliefs about intelligence, higher scores indicate incremental theories and lower scores indicate entity theories of emotion. ${ }^{1}$

\section{Emotion Regulation Self-Efficacy, Strategies, and Emotional Intensity}

To measure emotion regulation self-efficacy, participants read 10 scenarios regarding emotion-eliciting events drawn from daily collegiate life (e.g., taking an important exam, running into a former boyfriend or girlfriend) and rated how confident they were in their ability to control their emotions in each scenario $(\alpha=.82)$ on a $0-100$ scale $(0=$ cannot do at all, $100=$ certainly can do $)$.

Individual differences in habitual use of the emotion regulation strategies of cognitive reappraisal and expressive suppression were assessed with the Emotion Regulation Questionnaire (Gross \& John, 2003). The questionnaire includes six items for cognitive reappraisal (e.g., "I control my emotions by changing the way I think about the situation I'm in"; $\alpha=.82$ ) and four items for expressive suppression (e.g., "I control my emotions by not expressing them"; $\alpha=.70$ ). Finally, individual differences in emotional intensity were measured with Gross and John's (1998) 6-item scale (e.g., "I have strong emotions"; $\alpha=.74$ ).

\section{Part 2: Weekly Diaries of Emotional and Social Outcomes}

Participants completed up to 10 weekly assessments throughout the fall quarter $(M=6)$, submitting their reports at the end of each week through a specially designed Web site. Each week during the fall quarter, participants rated their emotional experiences and the degree of social support they received from friends and parents in the past week. Positive emotions were measured with four items: happy/pleased/contented, proud/accomplished/successful, cared about/loved/connected, interested/intellectually engaged/stimulated $(\alpha=.78)$. Negative emotions were also measured with four items: anxious/nervous, angry/irritated/pissed off, sad/depressed/ down, tired/fatigued $(\alpha=.76)$. In both cases, participants rated how much they felt each emotion in the past week on a 4-point scale $(0=$ not at all, $4=$ extremely $)$.

Social support was defined as the degree of emotional support students received from their friends at Stanford. Parental support was defined as the degree of emotional support students received from their parents. Both ratings were made on a 7-point scale $(1=$ no support, 7 = great support .

Weekly assessments were available for 236 students (57\% female, $43 \%$ male) who participated in Part 1 of this investigation. As expected, attrition analyses indicated that students who completed the weekly assessments did not differ significantly from students in our core sample on the main variables of interest, including implicit beliefs about emotion and emotion regulation self-efficacy.

\section{Part 3: Long-Term Outcomes Reported by Self and Peers}

\section{Self-Reported Outcomes: Positive and Negative Emotion, Adjustment, and Social Functioning}

Ratings were provided at the end of the final quarter of freshman year. Participants rated how often in the past quarter they experienced particular emotions on a 4 -point scale $(1=$ rarely or none of the time, $4=$ most or all of the time). Positive emotions were measured by ratings of happiness and interest $(\alpha=.71)$, and negative emotions were measured by ratings of anxiety, anger, and sadness $(\alpha=.64)$. Psychological well-being across different domains was measured by 9 items $(\alpha=.69)$ that tap domains of psychological well-being suggested by Ryff and Keyes (1995), such as environmental mastery and personal growth. Depressive symptoms were measured by the 10-item $(\alpha=.83)$ version of the Center of Epidemiological Studies Depression Scale (CES-D; Andresen, Malmgren, Carter, \& Patrick, 1994).

Following Astin (1993), social adjustment was defined for participants as the degree to which they felt they had adjusted to college and the degree to which they felt they fit in at Stanford; participants rated both on a 7 -point scale $(1=$ not very well, $7=$ very well), and the two ratings were averaged $(\alpha=.80)$. Loneliness was defined as feelings of "loneliness, isolation, or rejection," which participants rated on a 5 -point scale $(0=$ not at all, $4=$ extremely).

These data were available for 364 (59\% female, $41 \%$ male) students who participated in Part 1 of this investigation. Attrition analyses indicated that students who completed the end-of-year assessment did not differ significantly from students in our core sample on any of the variables of interest, including implicit beliefs about emotion and emotion regulation self-efficacy.

\section{Peer-Reported Outcomes: Positive and Negative Emotion, Adjustment, and Social Functioning}

Given time constraints, questions for peers were designed to be brief but as similar as possible to those used in the self-reports. To assess emotion in the past quarter, peers rated the target person's positive emotions $(\alpha=.50)$ and negative emotions $(\alpha=.66)$ by using the same emotions used in the self-reports. Psychological well-being was assessed by seven items $(\alpha=.67)$ that tap the domains suggested

\footnotetext{
${ }^{1}$ A reviewer wondered whether the two items on our measure that ask about control of emotion and the two items that ask about change of emotion might assess distinct aspects of implicit emotion beliefs. To find out, we correlated the mean of the two "control" items with the mean of the two "change" items and found these less reliable part scores were nonetheless strongly correlated $(r=.61, p<.001)$. Even more important, the pairwise interitem correlations across the two sets of items were as large as those within each set; that is, the four items did not form two distinct clusters but assessed a single underlying construct. Finally, to ensure that the control and change items related to external variables in the same way (as one would expect if they were tapping the same underlying construct), we repeated all analyses reported in this article twice, once with the aggregate of the two "control" items and once with the aggregate of the two "change" items instead of the total score. The pattern of results obtained for the total score was fully replicated by both of the two part scores, confirming that our measure assesses a single construct.
} 
by Ryff and Keyes (1995). To measure depressive symptoms, peers rated the degree to which the target felt depressed in the past quarter on a 5 -point scale $(0=$ not at all, $4=$ extremely). Finally, social adjustment was defined for the peers as the degree to which the target person seemed "settled in at Stanford," and loneliness was defined as the degree to which the target was "lonely and isolated" during the past quarter; the peers rated both social indices on a 5-point scale $(0=$ not at all, 4 = extremely).

Ratings from 2 or 3 knowledgeable peers were available for 163 of the participants who provided self-reported outcomes in Part 3 of the investigation. In total, students nominated 382 peers $(63 \%$ female, $37 \%$ male) who knew the target students well. Participants who provided ratings from $2-3$ peers did not differ significantly from those who did not provide ratings on all the variables of interest that were assessed in Part 1 of this investigation.

\section{Part 4: Emotion Regulation Self-Efficacy as a Mediator}

To test whether emotion regulation self-efficacy mediated the effects of implicit theories of emotion on emotional and social functioning, we followed the steps outlined by Baron and Kenny (1986) and by Krull and MacKinnon (1999, 2001). First, in Part 1, we tested whether implicit theories of emotion (i.e., the predictor) were related to emotion regulation self-efficacy (i.e., the hypothesized mediator). Second, in Parts 2 and 3, we tested whether implicit theories of emotion were linked to emotional and social outcome variables. Third, in Part 4, we tested whether emotion regulation self-efficacy was associated with the outcomes described in Parts 2 and 3 in regression analyses that also included implicit theories of emotion.

Full mediation was indicated when implicit theories of emotion no longer predicted an outcome variable after controlling for emotion regulation self-efficacy. Partial mediation was indicated when the association between implicit theories of emotion and an outcome variable was reduced substantially after controlling for emotion regulation self-efficacy. The significance of the mediation effects were evaluated with Sobel (1982) tests, as recommended by Krull and MacKinnon (1999, 2001).

\section{Results}

\section{Part 1: Relations to Emotion Regulation Before the Transition to College}

\section{Implicit Theories of Emotion and Intelligence}

The means and standard deviations of individual differences in implicit theories of emotion as well as their intercorrelations are presented in Table 1. As shown in the table and consistent with prior work on implicit theories of intelligence (Dweck et al., 1995a), participants in our sample, on average, tended to view intelligence as somewhat malleable $(M=3.17)$. As expected, participants tended to view emotions as more malleable $(M=$ 3.33 ) than intelligence, as indicated by a paired-samples $t$ test, $t(435)=2.71, p<.01$.

The correlation between implicit theories of intelligence and emotion was, as expected, positive but modest in size, indicating that the two are related but clearly separable from one another. Because implicit theories of emotion and intelligence were significantly correlated, we controlled for implicit theories of intelli-
Table 1

Cross-Sectional Correlations Among Incremental Theories of Emotion and Intelligence and Emotion Regulation Variables at the Beginning of the Longitudinal Study (Part 1)

\begin{tabular}{llllll}
\hline \multicolumn{1}{c}{ Variable } & 1 & 2 & 3 & 4 & 5 \\
\hline \multicolumn{5}{c}{ Incremental theories } \\
1. Emotion & - & & & \\
2. Intelligence & $.27^{*}$ & - & & \\
\hline \multicolumn{7}{c}{ Emotion regulation } \\
3. Self-efficacy & $.24^{*}$ & $.14^{*}$ & $-1^{*}$ & - & \\
4. Reappraisal & $.35^{*}$ & .07 & $.21^{*}$ & -.03 & - \\
4. Suppression & .04 & -.01 & .00 & & \\
${ }^{*} p<.05$. & & & &
\end{tabular}

gence in subsequent analyses to ensure independent effects. As in prior work, implicit theories of emotion and intelligence were not consistently related to either gender or ethnicity.

\section{Emotion Regulation and Implicit Theories of Emotion and Intelligence}

Table 1 presents the correlations among implicit theories of emotion and intelligence and emotion regulation variables. Consistent with our formulation, incremental theories of emotion were associated with greater emotion regulation self-efficacy. Selfefficacy was also positively related to incremental theories of intelligence. However, the association between emotion regulation self-efficacy and incremental theories of emotion remained significant and essentially unchanged when the effects of implicit theories of intelligence were controlled $(p r=.21, p<.05)$. On the other hand, implicit theories of intelligence were no longer significantly correlated with emotion regulation self-efficacy after partialling out implicit theories of emotion $(\mathrm{pr}=.08, n s)$.

As expected, incremental theories of emotion, but not intelligence, were positively associated with habitual use of cognitive reappraisal. Implicit theories of emotion, however, were not related to expressive suppression. These associations remained unchanged even after we controlled for implicit theories of intelligence (cognitive reappraisal: $p r=.34, p<.05$; expressive suppression: $p r=.04, n s$ ).

Finally, individuals with more intense emotional experiences might be more likely to develop entity theories of emotion. Indeed, in our sample, incremental theories of emotion were negatively associated with emotional intensity $(r=-.21, p<.05)$. To examine whether emotional intensity might drive the link between implicit theories of emotion and emotion regulation, we partialled out emotional intensity. As expected, all the effects reported in Table 1 remained significant and were essentially unchanged in effect sizes (i.e., emotion regulation self-efficacy: $p r=.20$; $\operatorname{cog}$ nitive reappraisal: $p r=.35$; expressive suppression: $p r=-.02$ ). Thus, the associations between implicit theories of emotion and individual differences in emotion regulation could not be explained simply by underlying differences in the intensity of the individual's emotional experiences. 
The results of Part 1 indicate that students entered college holding rather different beliefs about the malleable nature of emotions. Moreover, those who viewed emotions as malleable (vs. fixed) felt a greater sense of self-efficacy in regulating their emotions and used cognitive reappraisal more frequently to do so. In Part 2, we examine the links between implicit theories and students' emotional and social experiences during their first academic term in college.

\section{Part 2: Weekly Diaries of Emotional and Social Outcomes}

\section{Data Analysis}

Individual growth modeling is a type of multilevel modeling (also known as mixed or hierarchical linear modeling) that estimates individual-level trajectories as well as the sample-level trajectory (Singer \& Willett, 2003). The analysis of multilevel data is accomplished by using one- and two-level models. The Level 1 model estimates variations in an outcome variable (e.g., positive emotion) as a function of time (e.g., week in the academic quarter). Such models include an intercept $\left(\pi_{\mathrm{Oi}}\right)$ that describes an individual's average level on the outcome variable across time and a time-varying covariate $\left(\pi_{1 \mathrm{i}}\right)$ that captures the magnitude of timedependent changes. "Week in the term" was the variable that represented time in our models. Following Singer and Willett (2003), week was centered at the sample mean (5.5) across all measurement occasions (see also Kreft, DeLeeuw, \& Aiken, 1995). The Level 1 model took the following form:

$$
\mathrm{Y}_{\mathrm{ij}}=\pi_{0 \mathrm{i}}+\pi_{1 \mathrm{i}}(\mathrm{WEEK}-5.5)+\varepsilon_{\mathrm{ij}} .
$$

The Level 2 model estimates individual differences in the Level 1 parameters as a function of between-subjects variables. Given that implicit theories of emotion and intelligence were correlated in Part 1, implicit theories of intelligence were included as a control in all Level 2 models. Scores on implicit theories were centered (see Singer \& Willett, 2003). Level 2 models took the following form:

$$
\begin{gathered}
\pi_{0 \mathrm{i}}=\gamma_{01 \text { Imotionsi }}+\gamma_{02 \text { INTELligencei }}+\zeta_{0 \mathrm{i}} . \\
\pi_{1 \mathrm{i}}=\gamma_{10}+\gamma_{11 \mathrm{EmotionSi}}+\gamma_{12 \text { INTElligencei }}+\zeta_{1 \mathrm{i}} .
\end{gathered}
$$

We tested four separate linear mixed models, one for each dependent measure, as described in the following paragraphs. ${ }^{2}$ All models were tested with the linear mixed models procedure in SPSS 11.5 (SPSS, Inc., 2002).

\section{Positive and Negative Emotion Experiences}

We examined a linear mixed model in which positive emotions were entered as the outcome variable, with centered week, implicit theories of emotion, and implicit theories of intelligence as predictors. As expected, implicit theories of emotion were a significant predictor of positive emotions $(\gamma=.11), t(238)=2.60, p<$ .05 . To illustrate this relationship, we computed estimated values separately for individuals high $(+1 S D)$ and low $(-1 S D)$ in incremental theories of emotion (Aiken \& West, 1991), with all other variables set to their mean level (i.e., zero). As shown in Figure 2, individuals who held entity (vs. incremental) theories of emotion experienced fewer positive emotions throughout the term. This was the case even after controlling for the effects of theories of intelligence. Implicit theories of emotion did not interact with week, $t(188)<1$, indicating that the effect on positive emotion experience was consistent throughout the first academic term.

In a second linear mixed model, negative emotions were entered as the outcome variable. Implicit theories of emotion were again a significant predictor of negative emotions $(\gamma=-.12), t(234)=$ 2.45, $p<.05$. As shown in Figure 2, individuals who held entity (vs. incremental) theories of emotion experienced more negative emotions throughout the academic term. This effect was found even after controlling for implicit theories of intelligence. Again, implicit theories of emotion did not interact with week, $t(193)<$ 1 , indicating that the effect on negative emotions was consistent throughout the academic term.

\section{Social Support From College Friends and Parental Support}

We ran an additional model, with support from college friends as the outcome variable. The Week $\times$ Implicit Theories of Emotion interaction was significant $(\gamma=.05), t(180)=2.66, p<.05$, indicating that the change trajectory of emotional support over the course of the academic term varied as a function of individual differences in implicit theories of emotion. To illustrate this trajectory, we computed separate estimated values for the first and last week in the term, separately for individuals high $(+1 S D)$ and low $(-1 S D)$ in incremental theories of emotion (Aiken \& West, 1991). As shown in Figure 3, as time went by, individuals who held entity theories of emotion received less and less support from their new college friends. On the other hand, as individuals with incremental theories of emotion progressed through the quarter, they received gradually increasing support from their new college friends.

In a separate model, we examined support from parents as the outcome variable. As expected, there were no significant effects for implicit theories of emotion. To test whether implicit theories of emotion still affected social support from college friends even when weekly parental support was controlled, we ran an additional model in which parental support was also centered as a Level 1 predictor. The Week $\times$ Implicit Theories of Emotion interaction remained significant, with the same effect size $(\gamma=.05), t(181)=$ 2.66, $p<.05$. This finding indicates that implicit theories of emotion were relevant to social support in new college relationships, but not to all personal relationships, such as those that had been established prior to the beginning of college.

\section{Summary and Limitations}

The results of Part 2 indicate that early in the transition to college, implicit theories of emotion influence the emerging trajectory of emotional and social experiences. Over the course of several months, individuals who held entity theories of emotion, but not intelligence, experienced more negative and fewer positive emotions. Furthermore, as time went by, they received decreasing

\footnotetext{
2 The pattern of findings remained the same when the effects of gender and interactions with gender were included in the Level 2 models.
} 


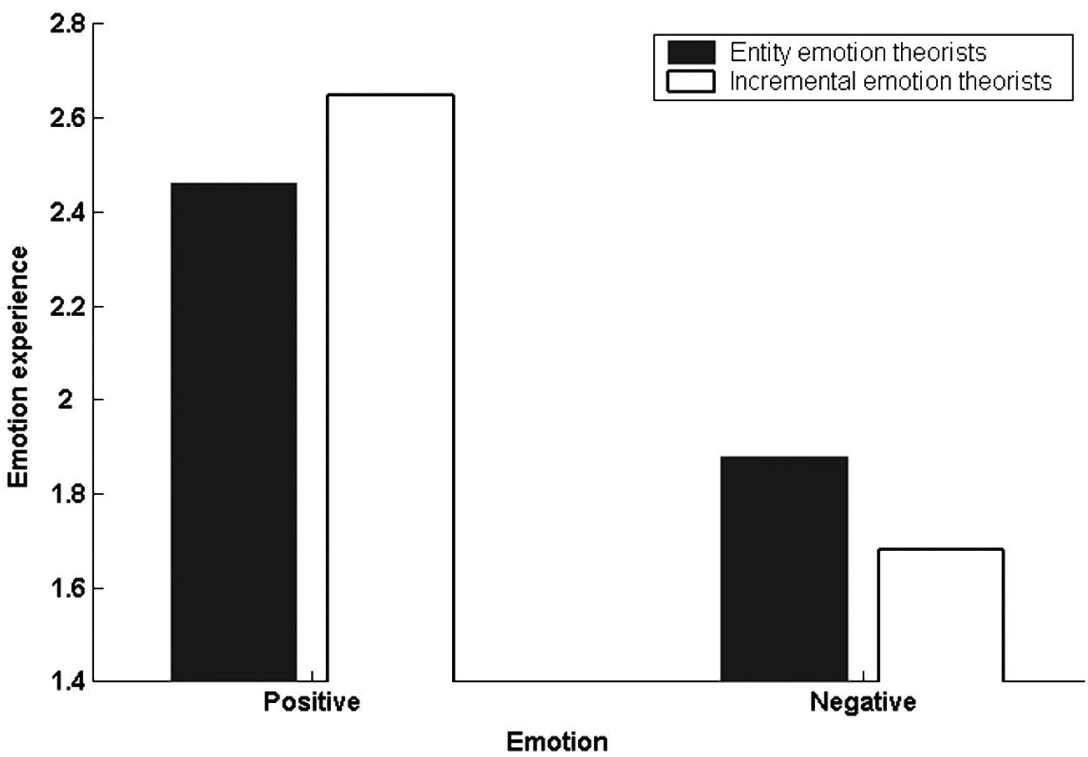

Figure 2. Estimated negative and positive emotion experience as a function of incremental versus entity theories of emotion (Part 2).

levels of support from their new college friends. On the other hand, individuals who held incremental theories of emotion experienced fewer negative, and more positive, emotions throughout the quarter. In addition, as the quarter progressed and their new college friends got to know them better, they received gradually and continuously increasing support. It is important to note that these effects were not applicable to all interpersonal relationships (e.g., those involving parents); instead, they were unique to new relationships with friends in college.

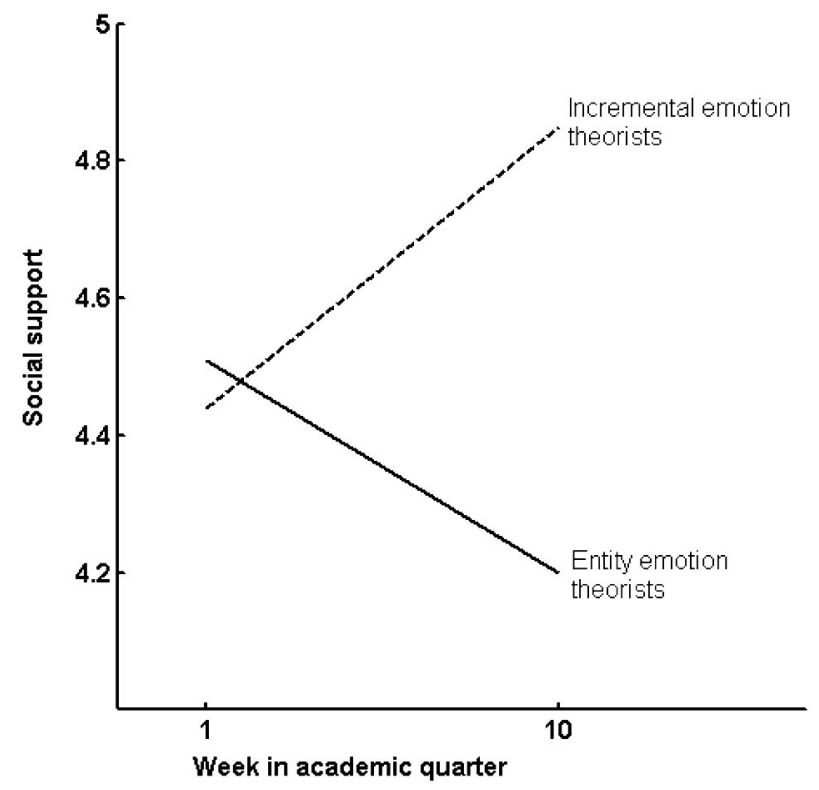

Figure 3. Estimated social support from college friends as a function of incremental versus entity theories of emotion and week in the academic term (Part 2).
Part 2 also has several limitations. First, the temporal scope was limited in that participants were followed only through the end of the first quarter of their freshman year. One important goal of Part 3 of the investigation, therefore, was to assess whether these implicit theories would predict outcomes even at the end of freshman year. Second, the considerable time commitment required of participants in continuous sampling procedures puts constraints on sample size (Scollon, Kim-Prieto, \& Diener, 2003). Although our sample was large enough to test our hypotheses, it is important to demonstrate that the effects emerge again in a relatively larger sample. In Part 3, therefore, we examine the implications of implicit theories of emotion with a larger sample of participants at the end of freshman year.

Finally, in Part 2, individuals reported on their own emotional and social experiences. Although such weekly reports provide a direct window into individuals' personal experience, it is important to broaden their ecological validity by examining peer-report evidence as well. Well-acquainted peers who have observed the individual in a wide range of emotion-eliciting situations and social settings can provide an important additional perspective on the individual's emotional experiences and social adjustment. Peer reports reflect behavioral trends the individual has manifested over time and across situations. Reports by peers are particularly important when assessing the individual's social functioning because such functioning involves relationships with the peers themselves (see also Cairns \& Green, 1979). Therefore, in Part 3, we also test whether findings for selfreported outcomes are replicated in peer ratings.

\section{Part 3: Long-Term Outcomes Reported by Self and Peers}

\section{Predicting Self-Reported Outcomes From Implicit Theories of Emotion and Intelligence}

Table 2 presents the longitudinal correlations of incremental theories of emotion and intelligence with self-reported emotional 
Table 2

Predicting Self-Reported Emotional and Social Outcomes at the End of Freshman Year: Longitudinal Correlations With Incremental Theories of Emotion and Intelligence (Part 3)

\begin{tabular}{lccc}
\hline & \multicolumn{3}{c}{ Incremental theories } \\
\cline { 2 - 4 } Outcome variable & Emotion & Intelligence & $\begin{array}{c}\text { Emotion } \\
\text { (partialling out } \\
\text { intelligence) }\end{array}$ \\
\hline Emotional and well-being & & & \\
$\quad$ outcomes & & & \\
Positive emotions & $.16^{*}$ & .04 & $.14^{*}$ \\
Negative emotions & $-.18^{*}$ & -.04 & $-.16^{*}$ \\
Well-being & $.24^{*}$ & .04 & $.20^{*}$ \\
Depression & $-.15^{*}$ & -.03 & $-.13^{*}$ \\
Social outcomes & $.12^{*}$ & -.06 & $.13^{*}$ \\
Social adjustment & $-.16^{*}$ & -.01 & $-.14^{*}$ \\
Loneliness & & & \\
\hline
\end{tabular}

${ }^{*} p<.05$

and social outcomes. Consistent with the results in Part 2, incremental theories of emotion, measured before coming to Stanford, were linked to more positive emotions and fewer negative emotions at the end of freshman year. In terms of broader well-being, incremental emotion theories predicted greater psychological wellbeing and lower rates of depression. Finally, in terms of social outcomes, incremental theories of emotion predicted better social adjustment and less loneliness. Unlike incremental theories of emotion, incremental theories of intelligence were not related to any of these outcomes. Moreover, as shown in Table 2, the effects of implicit theories of emotion remained essentially unchangedeven when the effects of implicit theories of intelligence were controlled. These findings indicate that cognitive beliefs about the malleability of emotion prior to college can foretell emotional and social adjustment to college almost 1 year later.

\section{Predicting Peer-Reported Outcomes From Implicit Theories of Emotion and Intelligence}

Table 3 presents the longitudinal correlations of the implicit theories with peer-reported outcomes. Replicating the pattern found with self-reports, peers reported that individuals with incremental theories of emotion had more positive emotions and less negative emotions. Peers also rated individuals with incremental theories of emotion as greater in psychological well-being and as less depressed. Corroborating self-reports, peers rated individuals holding incremental theories of emotion as socially better adjusted and as less lonely during the last quarter of freshman year. As with self-reports, peer-rated outcomes were not related to implicit theories of intelligence, and the correlations with implicit theories of emotion remained essentially unchanged when controlling for implicit theories of intelligence.

Overall, across outcome variables, the pattern of findings in reports by knowledgeable peers closely paralleled those in the self-reports. Such consistency substantially buttresses our confidence in the present findings and, by implication, further corroborates the findings in Part 2. Implicit theories of emotion that were held before entering college predicted critical psychological and social outcomes nearly 1 year later, regardless of data source.

\section{Part 4: Emotion Regulation Self-Efficacy as a Mediator}

\section{Mediation of Self-Reported Emotional Outcomes}

To test for mediation of emotional outcomes, we conducted six mediation tests, two tests for emotion experiences during the first quarter and four tests at the end of freshman year. Overall, emotion regulation self-efficacy significantly mediated five of these emotion and well-being outcomes.

Immediate emotion effects during the first quarter. We first tested whether emotion regulation self-efficacy mediated the effects of implicit theories of emotion on negative or positive emotions (Part 2). Specifically, we ran linear mixed models that included implicit theories of emotion and emotion regulation selfefficacy as Level 2 predictors and negative emotion or positive emotion as the outcome variable. Higher levels of emotion regulation self-efficacy predicted less negative emotion $(\gamma=-.01)$, $t(230)=5.19, p<.05$, as did implicit theories of emotion. As expected, Sobel tests for mediation indicated that the effect of implicit theories of emotion on negative emotion was significantly reduced (Sobel's $z=3.98, p<.05$ ). Emotion regulation selfefficacy did not significantly predict positive emotion, but the effect was in the right direction $(\gamma=.005), t(239)=1.89, p=.06$. The Sobel test in this case was not significant (Sobel's $z=1.62$, $n s)$.

Long-term emotion effects. To test for mediation of outcomes at the end of freshman year (Part 3), we first conducted regression analyses predicting negative emotion, positive emotion, psychological well-being, and depression reported at the end of freshman year from both implicit theories of emotion and emotion regulation self-efficacy. Emotion regulation self-efficacy predicted negative emotions $(\beta=-.10, p<.05)$, positive emotions $(\beta=.19, p<$ $.05)$, psychological well-being $(\beta=.25, p<.05)$, and depression $(\beta=-.22, p<.05)$ at the end of freshman year. In all these cases, implicit theories of emotion remained a significant predictor when

Table 3

Predicting Peer-Reported Emotional and Social Outcomes at the End of Freshman Year: Longitudinal Correlations With Incremental Theories of Emotion and Intelligence (Part 3)

\begin{tabular}{|c|c|c|c|}
\hline \multirow[b]{2}{*}{ Outcome variable } & \multicolumn{3}{|c|}{ Incremental theory } \\
\hline & Emotion & Intelligence & $\begin{array}{c}\text { Emotion } \\
\text { (partialling } \\
\text { out } \\
\text { intelligence) }\end{array}$ \\
\hline \multicolumn{4}{|c|}{$\begin{array}{l}\text { Emotion and well-being } \\
\text { outcomes }\end{array}$} \\
\hline Positive emotions & $.19^{\dagger}$ & .10 & $.18^{\dagger}$ \\
\hline Negative emotions & $-.15^{\dagger}$ & .05 & $-.17^{\dagger}$ \\
\hline Well-being & $.16^{\dagger}$ & .05 & $.15^{\dagger}$ \\
\hline Depression & $-.14^{\dagger}$ & .08 & $-.15^{\dagger}$ \\
\hline \multicolumn{4}{|l|}{ Social outcomes } \\
\hline Social adjustment & $.24^{\dagger}$ & .03 & $.24^{\dagger}$ \\
\hline Loneliness & $-.17^{\dagger}$ & .06 & $-.18^{\dagger}$ \\
\hline
\end{tabular}

${ }^{\dagger} p<.05$, one-tailed. 
emotion regulation self-efficacy was included in the regression. However, subsequent Sobel tests indicated that in all cases the effects of implicit theories of emotion were significantly reduced (Sobel's $z \mathrm{~s}=3.89,2.38,4.48$, and 3.82, respectively, $p \mathrm{~s}<.05$ ). Taken together, these findings suggest that emotion regulation self-efficacy partially mediated the effects of implicit theories of emotion on negative emotion, positive emotion, psychological well-being, and depression at the end of freshman year.

\section{Mediation of Self-Reported Social Outcomes}

None of the social outcomes were mediated by individual differences in emotion regulation self-efficacy. Emotion regulation self-efficacy predicted neither the effects of implicit theories of emotion on social support during the first academic term (Part 2) nor the loneliness or social adjustment at the end of freshman year (Part 3). Moreover, none of the Sobel tests for mediation were significant in these cases.

\section{Mediation of Peer-Reported Emotional and Social Outcomes}

The mediation analyses above demonstrate that emotion regulation self-efficacy mediated the link between implicit emotion theories and emotional, but not social, outcomes. Emotional and social outcomes at the end of freshman year were also reported by peers, although the reliabilities of peer reports were generally lower because of the smaller number of items included. Therefore, to test whether the same mediation pattern found with self-reported outcomes was replicated with peer-reported outcomes, we first created an aggregated peer-reported emotion outcome by reverse scoring peer-reported negative emotions and depression and averaging the reverse scores with positive emotions and well-being so that higher scores on the emotion aggregate reflect more positive affect. As expected, the resulting measure was substantially more reliable than each of its components $(\alpha=.81)$. Similarly, we created an aggregated score of peer-reported social outcomes by averaging across social adjustment and reverse-scored loneliness $(\alpha=.74)$.

To test for mediation of peer-reported emotional outcomes, we first conducted regression analyses predicting peer-reported emotional outcomes from both implicit theories of emotion and emotion regulation self-efficacy. Emotion regulation self-efficacy predicted emotional outcomes $(\beta=.19, p<.05)$. However, implicit theories of emotion were no longer a significant predictor when emotion regulation self-efficacy was included in the regression. A subsequent Sobel test indicated that the effects of implicit theories of emotion were significantly reduced (Sobel's $z=2.08, p<.05$ ).

The above mediation analysis was repeated with the social outcome measure. As with self-reported social outcomes, peerreported social outcomes were not mediated by individual differences in emotion regulation self-efficacy. Emotion regulation selfefficacy did not predict the effects of implicit theories of emotion on peer-reported social outcomes, and the respective Sobel test for mediation was not significant. Thus, as with the self-reported outcomes, emotion regulation self-efficacy mediated peer-reported emotional, but not social, outcomes. Such findings provide important support to the validity of our findings.

\section{Summary}

Emotion regulation self-efficacy generally mediated the effects of implicit emotion theories on emotional outcomes but not on social outcomes. In general, this pattern was consistent over time: It was obtained when examining outcomes during the first term (i.e., in Part 2) as well as at the end of freshman year (i.e., in Part 3). Such mediational patterns were found for both self-reported and peer-reported outcomes. Nevertheless, all mediation paths were partial, suggesting that emotion regulation self-efficacy is likely only one of several potential mediators.

\section{Discussion}

Individuals differ in their implicit theories of emotion. Almost $40 \%$ of the students in our sample believed emotions to be relatively fixed (i.e., scored above the scale midpoint), whereas the rest believed them to be relatively malleable. These beliefs had important implications for emotion experience, social functioning, and general adaptation during a major life transition, namely the transition to college.

Before they entered college, individuals with entity (vs. incremental) theories of emotion reported using cognitive reappraisal less frequently to control their emotions and had a weaker sense of emotion regulation self-efficacy (Part 1). Then, during the initial period of the transition to college, implicit beliefs about emotion helped launch experiential trajectories (Part 2). In particular, individuals with entity (vs. incremental) theories of emotion experienced fewer positive and more negative emotions. In addition, as the term progressed, these individuals received less and less social support from college friends, whereas those who held incremental theories of emotion received increasing social support. The emotional and social benefits that accrued during the first academic term were sustained all the way until the end of freshman year. At the end of the year, individuals who had held entity (vs. incremental) theories of emotion before entering college had less favorable emotion experiences, lower well-being, greater depression, more loneliness, and poorer social adjustment as was evident in both self and peer-reports (Part 3).

How do beliefs about the controllability of emotion lead to increased depression and loneliness almost a year following their assessment? In Part 4, we provided preliminary findings that suggest that emotion regulation self-efficacy might serve as the link between implicit emotion theories and their emotional outcomes. Emotion regulation self-efficacy, however, did not mediate the link between implicit theories of emotion and their social outcomes.

\section{Beliefs About Emotion and Their Implications}

Our findings demonstrate that beliefs about the controllability of emotion are linked to important emotional and social outcomes. By demonstrating such links, the present findings extend prior research on cognitive beliefs in emotional experience (e.g., BenArtzi \& Mikulincer, 1995; Robinson \& Clore, 2002). Prior studies have examined general beliefs about the nature of emotion, examining beliefs about controllability, predictability, stability, and other attributes of emotion (e.g., Ben-Artzi \& Mikulincer, 1996; Mayer \& Gaschke, 1988). Other research has linked emotional 
outcomes to self-beliefs about personal abilities. For example, Beck (1996) suggested that emotional disorders arise from dysfunctional self-beliefs. Furthermore, Wells and Matthews (1996) suggested that maladaptive assumptions about one's ability to change can contribute to pathological outcomes.

The present findings extend such prior approaches in several important ways. First, some of the prior research has examined patterns of beliefs about emotion other than focusing on the implications of beliefs about malleability, per se, as distinct from beliefs about stability and predictability (e.g., Ben-Artzi \& Mikulincer, 1995). Second, with respect to beliefs about malleability, prior research has focused primarily on self-specific beliefs. However, general beliefs likely precede self-specific beliefs. According to the health belief model (Rosenstock, 1974; Rosenstock et al., 1988), general beliefs about the malleability of health conditions are assumed to be a necessary precursor of subsequent beliefs about self-efficacy. In the emotion domain, the belief that emotions are malleable could be an important precursor of beliefs about emotion-specific capabilities in the self and in others. Consistent with these assumptions, we found that emotion regulation self-efficacy mediated the link between implicit theories of emotion and emotional outcomes.

Third, whereas self-beliefs are about the self, general beliefs have implications for both the way a person views him- or herself and the way a person perceives and responds to others. By exploring general beliefs about emotions, we were able to demonstrate important consequences in both the intrapersonal and the interpersonal domains. A final point is that previous research on selfbeliefs and emotional outcomes has focused exclusively on their maladaptive implications. Our findings, on the other hand, suggest that general beliefs about emotion can have both adaptive and maladaptive implications. Our research is, therefore, of relevance to psychologists interested in unhealthy as well as in healthy functioning.

The present findings also encourage the exploration of other beliefs about emotion, including beliefs about mixed attributes such as emotional intelligence. In this respect, it is worth noting that emotion, unlike intelligence, is transient and variable. Building on prior work on implicit theories, in this investigation we examined beliefs about the controllability of emotion. It might also be useful, in the future, to explore beliefs about the stability of emotion, as well as other attributes.

\section{Exploring Underlying Mechanisms}

We found that the links between implicit emotion theories and emotional experience were partially mediated by emotion regulation self-efficacy. Emotion regulation self-efficacy, however, is only one of many factors that could mediate the link between implicit theories of emotion and emotional experience. If the belief that emotions are malleable is a prerequisite for beliefs about one's personal ability to regulate one's emotions, it could underlie a host of emotion regulation processes, any one of which could influence emotion either separately or in combination. Future research should examine other emotion regulation variables as possible mediators and test whether some are more prominent than others.

The present investigation provides initial support for one possible mediation model. Clearly, however, there are many other mediation models that need to be tested. In future studies, it might be useful to assess implicit theories of emotion, potential mediators, and relevant outcomes in each of several assessments that are spread over time. Doing so would minimize any assessmentspecific effects as well as enable tests of reversed causal arrows (e.g., might the link between implicit theories of emotion and self-efficacy in emotion regulation be mediated by emotion experience?).

In the present investigation, although emotion regulation selfefficacy mediated the link between implicit emotion theories and emotional experiences, it did not mediate their links to social functioning, and this was true for outcome variables from both Parts 2 and 3. This dissociation was replicated with both selfreported outcomes and peer-reported outcomes, attesting to the reliability and validity of the findings. This replicated dissociation between emotional and social effects raises the intriguing possibility that different pathways might underlie the intra- and the interpersonal implications of implicit theories of emotion.

An important question for future research, therefore, concerns the factors that mediate the social outcomes of implicit theories of emotion. We suggest that the mediators of personal and intrapsychic outcomes (e.g., emotions, subjective well-being) involve beliefs about the self (e.g., emotion regulation self-efficacy), and our findings begin to build some support for this hypothesis. Conversely, mediators of social outcomes (e.g., social support) might involve beliefs about others (e.g., interpersonal trust). Exploring such possible mediators is an important task for future research.

\section{Ruling Out Alternative Hypotheses}

In the present investigation, we were able to rule out some alternative accounts of the associations between implicit emotion theories and adaptive functioning. First, although implicit theories are assumed to be domain specific (Dweck, 1999), they are clearly based on similar worldviews (Dweck et al., 1995a). Therefore, one alternative account is that the effects of implicit theories of emotion are driven by the nature of implicit theories more generally or, specifically, by the well-studied beliefs about the malleability of intelligence. Our findings show little support for this hypothesis. Although these two kinds of implicit theories were moderately correlated (Part 1), the present effects were not driven by implicit theories of intelligence but instead were specifically and uniquely the result of implicit theories of emotion, as we were able to show consistently in our investigation.

A second alternative account centers on a third variable that potentially underlies implicit emotion theories, emotion regulation, and emotional experience as well. One such variable is emotional intensity. People with very strong emotions might be less able to regulate their emotions and might therefore view emotions as generally more difficult for people to control. As demonstrated in Part 1, however, the correlation between implicit theories of emotion and emotional intensity was small. Even more important, the associations between implicit emotion theories and all emotion regulation variables remained unchanged even after controlling for emotional intensity.

Finally, prior research has linked emotion regulation concurrently to both emotional and social outcomes (e.g., Gross \& John, 2003). Thus, it is possible that individual differences in emotion regulation, such as in emotion regulation self-efficacy, underlie both implicit theories of emotion and emotional and social conse- 
quences. By showing that the link between implicit theories of emotion and social outcomes was not mediated by emotion regulation self-efficacy, we were able to rule out this and similar alternative accounts. In other words, beliefs about the malleable nature of emotion were associated with emotion regulation selfefficacy, but they also had unique and important implications to social functioning for which emotion regulation self-efficacy could not account.

\section{Limitations and Future Directions}

Research on implicit theories joins a growing body of research on the role of beliefs in self-regulation (e.g., Beck, 1996; Rosenstock, 1974; Wells \& Matthews, 1996). Within this framework, our findings link implicit beliefs about emotion to emotion regulation, to emotion experience, and to social functioning. Consistent with recent evidence (e.g., Gross \& John, 2003; Mikulincer, Shaver, \& Pereg, 2003; Tamir, 2005), our findings emphasize the importance of individual differences in emotion regulation. In doing so, the present findings might help explain why some people are less successful than others at modifying their emotions. For example, individuals who hold entity theories of emotion might be less aware of, and open to, the possibility of changing their emotions and, therefore, less responsive to attempts by close others or by health professionals to modify maladaptive emotion patterns. Exploring such pragmatic implications and ways to devise appropriate interventions is an important task for future research.

In our investigation, implicit theories of emotion were positively associated with emotion regulation self-efficacy and cognitive reappraisal. However, it is important to acknowledge that such links might not necessarily generalize to all emotion regulation variables. In this respect, in Part 1 of this investigation, we found that implicit theories of emotion were related to cognitive reappraisal, which concerns the modification of subsequent emotion experience, but were not related to expressive suppression, which concerns the modification of overt emotion expression. Although such findings are consistent with existing evidence for the dissociation between reappraisal and suppression (e.g., Gross \& John, 2003), they suggest that individuals might differ in their implicit beliefs about the experience versus the expression of emotion. Future research, therefore, should directly examine whether individuals have distinct beliefs about the malleable nature of emotion experience compared with emotion expression.

An important advantage of the present investigation is its longitudinal, multimethod design. These features, however, come at a price. Specifically, our sample size was often limited and peerreported outcomes had relatively low reliability because of the limited number of items that were included in the assessments. Such limitations might also account for the relatively small effect sizes. In the future, it is important to examine the implications of implicit theories of emotion through the use of multiple items in the assessments as well as larger sample sizes.

The longitudinal design of the present investigation allowed us to test certain hypotheses about the real-life implications of implicit theories of emotion as they evolved over time. One limitation of this design, however, is that it cannot provide direct support for causal accounts. Although causal conclusions are premature, our findings so far are certainly consistent with the view that implicit theories of emotion exert a causal influence. This view is also consistent with empirical evidence for the causal role of implicit theories in guiding self-regulation (see Dweck, 1999; Dweck et al., 1995a) and with leading models of behavioral change (e.g., Rosenstock, 1974). Future research should test the causal hypothesis more directly, for example, by experimentally manipulating beliefs about the controllability of emotion and by testing the effects of such manipulations on subsequent emotion regulation and experience.

The present investigation demonstrates that implicit theories of emotion as measured prior to the transition to college were associated with noteworthy differences in adjustment to college. However, the present investigation did not allow us to fully test the extent to which implicit theories of emotion predicted changes in adjustment during (vs. prior to) college. One exception, however, concerns the impact of implicit theories of emotion on the development of social relationships. By examining the nature of these relationships as they were being created, we were able to demonstrate that incremental theories of emotion contributed to increasing social support during the first academic term. However, because we did not include measures of emotional and social adjustment in Part 1 of the investigation, we were unable to test other models that control for baseline levels. By assessing predictors and outcomes at every longitudinal assessment, future research should examine whether implicit theories of emotion predict levels of adjustment, changes in adjustment, or both.

Consistent with findings in other domains, the present findings demonstrate positive implications to incremental beliefs about emotion. It is important to emphasize, however, that we subscribe to the idea that all beliefs have their costs and benefits. Some potential costs of incremental theories are discussed in Dweck et al. (1995b). Building on this discussion, it might be possible, for instance, that incremental theories of emotion are costly for individuals who find it difficult to come to terms with their own limitations. If a student believes that emotions are malleable yet repeatedly fails in altering her emotions, the student might end up feeling very incompetent. Examining the potential costs and benefits of implicit theories of emotion and the extent to which they vary as a function of stable dispositions are important tasks for future research.

Finally, given the implications of implicit theories of emotion, one important topic for future research concerns the precursors and the developmental trajectory of such theories. In other words, where do implicit theories of emotion come from and how do they develop? On the basis of the analysis of the origins and development of implicit theories provided in Dweck et al. (1995b), it is plausible that both temperamental differences as well as socialization practices can contribute to the development of implicit theories of emotion. For instance, might individuals who often experience unpleasant emotion (e.g., depression) be more prone to develop entity theories of emotion? In addition, might childrearing practices that encourage emotion regulation through constructive responses promote the development of incremental theories of emotion? These and other potential antecedents remain to be explored.

\section{Conclusions}

"He is able who thinks he is able," noted Buddha, acknowledging the directive power of belief. The present investigation dem- 
onstrates that people differ in their beliefs about the malleability of emotions. Consistent with Buddha's insight, those who believe that people can control their emotions are themselves more effective in controlling their emotions and enjoy long-term emotional and social benefits. By examining implicit beliefs in the emotion domain, the present findings shed important new light on the cognitive precursors of emotion regulation.

\section{References}

Aiken, L. S., \& West, S. G. (1991). Multiple regression: Testing and interpreting interactions. Thousand Oaks, CA: Sage.

Andresen, E. M., Malmgren, J. A., Carter, W. B., \& Patrick, D. B. (1994). Screening for depression in well older adults: Evaluation of a short form of the CES-D. American Journal of Preventive Medicine, 10, 77-84.

Astin, A. W. (1993). What matters in college? Four critical years revisited. San Francisco, CA: Jossey-Bass.

Bandura, A. (1986). Social foundations of thought and action: A social cognitive theory. Englewood Cliffs, NJ: Prentice Hall.

Baron, R. M., \& Kenny, D. A. (1986). The moderator-mediator variable distinction in social psychological research: Conceptual, strategic, and statistical considerations. Journal of Personality and Social Psychology, 51, 1173-1182.

Beck, A. T. (1996). Beyond belief: A theory of modes, personality, and psychopathology. In P. M. Salkovskis (Ed.), Frontiers of cognitive therapy (pp. 1-25). New York: Guilford Press.

Bedier, J. (1900). Le roman de Tristan et Iseult [The romance of Tristan and Isolde]. Paris: Paris L'edition D'art.

Beer, J. S. (2002). Implicit self-theories of shyness. Journal of Personality and Social Psychology, 83, 1009-1024.

Ben-Artzi, E., \& Mikulincer, M. (1995). Lay theories of emotion: I. Conceptualization and measurement. Imagination, Cognition and Personality, 15, 249-271.

Ben-Artzi, E., \& Mikulincer, M. (1996). Lay theories of emotion: IV. Reactions to negative and positive emotional episodes. Imagination, Cognition, and Personality, 16, 89-113.

Cairns, R. B., \& Green, J. A. (1979). How to assess personality and social patterns: Observations or ratings. In R. B. Cairns (Ed.), The analysis of social interactions: Methods, issues, and illustrations (pp. 209-226). Hillsdale, NJ: Erlbaum.

Cantor, N., Norem, J. K., Niedenthal, P. M., Langston, C. A., \& Brower, A. M. (1987). Life tasks and cognitive strategies in a life transition. Journal of Personality and Social Psychology, 53, 1178-1191.

Catanzaro, S. J., \& Mearns, J. (1990). Measuring generalized expectancies for negative mood regulation: Initial scale development and implications. Journal of Personality Assessment, 54, 546-563.

Chaplin, W. F., John, O. P., \& Goldberg, L. R. (1988). Conceptions of states and traits: Dimensional attributes with ideals as prototypes. Journal of Personality and Social Psychology, 54, 541-557.

Chiu, C. Y., Dweck, C. S., Tong, J. Y. Y., \& Fu, J. H. Y. (1997). Implicit theories and conceptions of morality. Journal of Personality and Social Psychology, 73, 923-940.

Chiu, C. Y., Hong, Y. Y., \& Dweck, C. S. (1997). Lay dispositionism and implicit theories of personality. Journal of Personality and Social Psychology, 73, 19-30.

Dresel, M. (2001). A longitudinal analysis of Dweck's motivation-processmodel in the classroom. Psychologische Beitrage, 43, 129-152.

Dweck, C. S. (1986). Motivational processes affecting learning. American Psychologist, 41, 1040-1048.

Dweck, C. S. (1996). Implicit theories as organizers of goals and behavior. In P. M. Gollwitzer \& J. A. Bargh (Eds.), The psychology of action: Linking cognition and motivation to behavior (pp. 69-90). New York: Guilford Press.
Dweck, C. S. (1999). Self-theories: Their role in motivation, personality, and development. New York: Psychology Press.

Dweck, C. S., Chiu, C. Y., \& Hong, Y. Y. (1995a). Implicit theories and their role in judgments and reactions: A world from two perspectives. Psychological Inquiry, 6, 267-285.

Dweck, C. S., Chiu, C. Y., \& Hong, Y. Y. (1995b). Implicit theories: Elaboration and extension of the model. Psychological Inquiry, 6, 322333.

Dweck, C. S., \& Leggett, E. L. (1988). A social-cognitive approach to motivation and personality. Psychological Review, 95, 256-273.

Erdley, C. A., \& Dweck, C. S. (1993). Children's implicit personality theories as predictors of their social judgments. Child Development, 64, 863-878.

Fowler, J. W., \& Peterson, P. L. (1981). Increasing reading persistence and altering attributional style of learned helpless children. Journal of Educational Psychology, 73, 251-260.

Gross, J. J. (1998). The emerging field of emotion regulation: An integrative review. Review of General Psychology, 2, 271-299.

Gross, J. J., \& John, O. P. (1998). Mapping the domain of expressivity: Multimethod evidence for a hierarchical model. Journal of Personality and Social Psychology, 74, 170-191.

Gross, J. J., \& John, O. P. (2003). Individual differences in two emotion regulation processes: Implications for affect, relationships, and wellbeing. Journal of Personality and Social Psychology, 85, 348-362.

Gross, J. J., John, O. P., \& Richards, J. M. (2000). The dissociation of emotion expression from emotion experience: A personality perspective. Personality and Social Psychology Bulletin, 26, 712-726.

Gross, J. J., Richards, J. M., \& John, O. P. (2006). Emotion regulation in everyday life. In D. K. Snyder, J. A. Simpson, \& J. N. Hughes (Eds.), Emotion regulation in couples and families: Pathways to dysfunction and health (pp. 13-35). Washington, DC: American Psychological Association.

Henderson, V. L., \& Dweck, C. S. (1990). Motivation and achievement. In S. Feldman \& G. R. Elliot (Eds.), At the threshold: The developing adolescent (pp. 308-329). Cambridge, MA: Harvard University Press.

Hochschild, A. R. (1979). Emotion work, feeling rules, and social structure. American Journal of Sociology, 85, 551-575.

Hong, Y. Y., Chiu, C. Y., Dweck, C. S., Lin, D. M. S., \& Wan, W. (1999). Implicit theories, attributions, and coping: A meaning system approach. Journal of Personality and Social Psychology, 77, 588-599.

Hong, Y. Y., Chiu, C. Y., Dweck, C. S., \& Sacks, R. (1997). Implicit theories and evaluative processes in person cognition. Journal of Experimental Social Psychology, 33, 296-323.

Kreft, I. G. G., DeLeeuw, J., \& Aiken, L. S. (1995). Variable centering in hierarchical linear models: Model parameterization, estimation, and interpretation. Multivariate Behavioral Research, 30, 1-21.

Krull, J. L., \& MacKinnon, D. P. (1999). Multi-level mediation modeling in group-based intervention studies. Evaluation Review, 23, 418-444.

Krull, J. L., \& MacKinnon, D. P. (2001). Multi-level modeling of individual and group level mediated effects. Multivariate Behavioral Research, 36, 249-277.

Lopes, P. N., Salovey, P., Cote, S., \& Beers, M. (2005). Emotion regulation ability and the quality of social interaction. Emotion, 5, 113-118.

Mayer, J. D., \& Gaschke, Y. N. (1988). The experience and metaexperience of mood. Journal of Personality and Social Psychology, 55, $102-111$.

Mikulincer, M., Shaver, P. R., \& Pereg, D. (2003). Attachment theory and affect regulation: The dynamics, development, and cognitive consequences of attachment-related strategies. Motivation and Emotion, 27, $77-102$.

Olson, J. M., Roese, N. J., \& Zanna, M. P. (1996). Expectancies. In E. T. Higgins \& A. W. Kruglanski (Eds.), Social psychology: Handbook of basic principles (pp. 211-238). New York: Guilford Press.

Robins, R. W., \& Pals, J. L. (2002). Implicit self-theories in the academic 
domain: Implications for goal orientation, attributions, affect, and selfesteem change. Self and Identity, 1, 313-336.

Robinson, M. D., \& Clore, G. L. (2002). Belief and feeling: Evidence for an accessibility model of emotional self-report. Psychological Bulletin, 128, 934-960.

Rosenstock, I. M. (1974). Historical origins of the health belief model. Health Education Monographs, 2, 328-335.

Rosenstock, I. M., Strecher, V. J., \& Becker, M. H. (1988). Social learning theory and the health belief model. Health Education Quarterly, 15, $175-183$.

Ryff, C. D., \& Keyes, C. L. M. (1995). The structure of psychological well-being revisited. Journal of Personality and Social Psychology, 69, $719-727$.

Scollon, C. N., Kim-Prieto, C., \& Diener, E. (2003). Experience sampling: Promises and pitfalls, strengths and weaknesses. Journal of Happiness Studies, 4, 5-34.

Seligman, M. E. P. (1975). Helplessness: On depression, development, and death. San Francisco: Freeman.

Shakespeare, W. (1992). Hamlet: Prince of Denmark. Washington, DC: The Folger Shakespeare Library. (Original work published 1603)

Shaver, P. R., Furman, W., \& Buhrmester, D. (1985). Transition to college: Network changes, social skills, and loneliness. In S. Duck \& D. Perlman (Eds.), Understanding personal relationships: An interdisciplinary approach (pp. 193-219). Thousand Oaks, CA: Sage.
Singer, J. D., \& Willett, J. B. (2003). Applied longitudinal data analysis: Modeling change and event occurrence. New York: Oxford University Press.

Sobel, M. E. (1982). Asymptotic intervals for indirect effects in structural equations models. In S. Leinhart (Ed.), Sociological methodology (pp. 290-312). San Francisco, CA: Jossey-Bass.

SPSS, Inc. (2002). SPSS (Version 11.5) [Computer software]. Chicago: Author.

Tabernero, C., \& Wood, R. E. (1999). Implicit theories versus the social construal of ability in self-regulation and performance on a complex task. Organizational Behavior and Human Decision Processes, 78, $104-127$.

Tamir, M. (2005). Don't worry, be happy? Neuroticism, trait-consistent affect regulation, and performance. Journal of Personality and Social Psychology, 89, 449-461.

Wells, A., \& Matthews, G. (1996). Modeling cognition in emotional disorder: The S-REF model. Behavior Research and Therapy, 34, 881888

Received November 11, 2005 Revision received October 23, 2006 Accepted November 2, 2006

\section{Low Publication Prices for APA Members and Affiliates}

Keeping you up-to-date. All APA Fellows, Members, Associates, and Student Affiliates receive-as part of their annual dues-subscriptions to the American Psychologist and APA Monitor. High School Teacher and International Affiliates receive subscriptions to the APA Monitor, and they may subscribe to the American Psychologist at a significantly reduced rate. In addition, all Members and Student Affiliates are eligible for savings of up to $60 \%$ (plus a journal credit) on all other APA journals, as well as significant discounts on subscriptions from cooperating societies and publishers (e.g., the American Association for Counseling and Development, Academic Press, and Human Sciences Press).

Essential resources. APA members and affiliates receive special rates for purchases of APA books, including the Publication Manual of the American Psychological Association, and on dozens of new topical books each year.

Other benefits of membership. Membership in APA also provides eligibility for competitive insurance plans, continuing education programs, reduced APA convention fees, and specialty divisions.

More information. Write to American Psychological Association, Membership Services, 750 First Street, NE, Washington, DC 20002-4242. 